\title{
Control de Constitucionalidad en el Sistema Africano y el Diálogo entre Jurisdiciones entre las Constituciones de los Países Lusofonos
}

\author{
Control of Constitutionality in the African System and the Dialogue among \\ Jurisdictions between the Constitutions of Lusophone Countries
}

\author{
Eduardo Biacchi Gomes ${ }^{1}$ \\ Edileny Tomé da Mata ${ }^{2}$ \\ ${ }^{1}$ Unibrasil Centro Universitário, Curitiba, PR, Brasil \\ ${ }^{2}$ Universidade Pablo de Olavide, Sevilla, Espanha
}

Resumen: Esto artículo aborda el control de constitucionalidad en el sistema africano de derechos humanos, para verificar cómo se lleva a cabo el diálogo entre jurisdicciones. Primero, hablaremos sobre la estructura orgánico-institucional del sistema. Además, introduciremos la interpretación del derecho regional e internacional por parte de los países de Angola, Cabo Verde, Guiné Bisssau, Mozambique y Santo Tomé y Príncipe. El método es el comparativo. Como conclusión, los ordenamientos jurídicos analizados permiten constitucionalmente la aplicación del derecho internacional de los derechos humanos dentro de sus ordenamientos, siendo necesario una conciencia de la sociedad de estos países sobre la importancia del tema.

Palabras clave: Control de Constitucionalidad. Sistema Africano de Derechos Humanos. Derecho comparativo.
Abstract: This article deals with the control of constitutionality in the African human rights system, to verify how the dialogue between jurisdictions is carried out. First, we will talk about the organic-institutional structure of the system. In addition, we will introduce the interpretation of regional and international law by countries such as Angola, Cape Verde, Bissau Guinea, Mozambique and São Tomé and Príncipe. The method is comparative. As a conclusion, the legal systems analyzed allow constitutionally the application of international human rights law within their systems, and it is necessary to make the society of these countries aware of the importance of the subject.

Keywords: Control of Constitutionality. African Human Rights System; Comparative Law.

Recebido em: 25/04/2020

Revisado em: 04/05/2020

Aprovado em: 06/05/2020

Direito autoral e licença de uso: Este artigo está licenciado sob uma Licença Creative Commons.Com essa licença você pode compartilhar, adaptar, para qualquer fim, desde que atribua a autoria da obra, forneça um link para a licença, e indicar se foram feitas alterações. 


\section{Introducción}

El tema abordado en este artículo es extremamente importante dentro de América Latina, hay que plantear la posibilidad de su aplicación en el Sistema Africano de Protección a los Derechos Humanos. Como parte del estudio, hablaremos sobre la estructura orgánico-institucional del sistema africano y, por otro, dos sistemas de control de constitucionalidad en el ámbito democrático siendo, el Mecanismo Africano de Revisión de Pares (APRM en sus siglas en inglés) y los mecanismos de control constitucional planteados en la Declaración de Lomé y en la Carta Africana sobre Democracia, Elecciones y Gobernanza. Además, introduciremos la interpretación del derecho regional e internacional por parte de las Constituciones de los países lusos-africanos (Angola, Cabo Verde, Guiné Bisssau, Mozambique y Santo Tomé y Príncipe).

Unión Africana (en adelante UA) es de las instituciones supranacionales menos conocidas no solamente en América y en Europa, sino incluso en el continente africano. Sobre este último las campañas desarrolladas por el Parlamento Panafricano a fin de divulgar los órganos del Parlamento, su funcionamiento $\mathrm{y}$ otras instituciones del sistema africano, confirma nuestra afirmación.

Así, hay que plantearnos, dentro de la idea de la existencia de un verdadero dialogo entre jurisdicciones, si las Constituciones de los Estados de lengua lusofóna autorizan el llamado control de constitucionalidad. Es decir: hay que plantear si en las constituciones de los Estados de lengua portuguesa encuentran artículos que puedan permitir la fiscalización y el control de la aplicación de las decisiones por el Tribunal del Sistema africano, dentro de los ordenamientos jurídicos de los Estados. Además, hay que preguntar como los jueces de los tribunales nacionales pueden o deben interpretar y aplicar las normas de derechos humanos dentro del sistema africano.

Así, la idea es de aplicar el método comparativo (derecho comparado), dedutivo e indutivo, de forma a buscar la mejor manera de llegarnos a las conclusiones propuestas, pasando por un análisis de las Constituciones de los países africanos de lengua portuguesa, así como 
por un análisis sobre los antecedentes al actual sistema supranacional africano, evolución histórica y contextualización jurídica.

\section{Antecedentes de la Unión Africana}

Hablar de la Unión Africana (UA) no es referirse a la institución creada en el año 2002, lo que significaría ser esquizofrénicos en nuestra memoria, sino de un sinfín de valores e instrumentos normativos anteriores al siglo XXI. Así, ya en el siglo XIII podemos mencionar una Carta adoptada en 1236 en Kurukan Fuga, ubicado en el antiguo imperio de Malí, que ya proclamaba, entre otros, el derecho a la vida, a la integridad física y a la propiedad (TARDIF, 2013, p. 140).

Además de este antecedente del siglo XIII cabe señalar que el sistema africano se inscribe en el marco del Movimiento panafricanista que tuvo sus inicios a partir del momento de la opresión esclavista y colonial blanca, es decir, desde el siglo XVI ${ }^{1}$. En este sentido, desde la proclamación de la República de Palmáres en Brasil entre los siglos XVII y XVIII y la Revolución haitiana entre los siglos XVIII y XIX hasta nuestros días venimos asistiendo varias manifestaciones populares e individuales cuyo objetivo es la "lucha por el reconocimiento de los legítimos derechos de los pueblos negros de África y de la diáspora".

También es menester señalar, tal como afirma Kabunda, que el panafricanismo se ha convertido en un cajón de sastre en el que combinan el panafricanismo idílico de sus padres afroamericanos, pasando por el panafricanismo minimalista hasta el panafricanismo maximalista (unidad supranacional). Señala el intelectual congoleño que es necesario además distinguir el "panafricanismo viciado y vaciado de contenido" o el "panafricanismo descafeinado" del neopanafricanismo cercano a las tesis maximalistas (KABUNDA, 2014, p. 16).

\footnotetext{
${ }^{1}$ Es menester señalar que la formulación material del Movimiento panafricanista tan sólo tuvo lugar en el siglo XX a través de intelectuales y políticos como Du Bois, Garvey, Nkruma, entre otros.
} 
Influenciados por el ideal panafricano del siglo XX, en los años cincuenta se crea la Unión de Estados Africanos (UEA), integrada únicamente por tres países, Malí, Gana y Guinea Conakry (OWONO-OKOMO, 2014, p. 51). La UEA estaba liderada por Kwame Nkruma, Ahmed Sekou Touré y Modibo Keita.

Tras la disolución en 1962 de la UEA, un año después se crea la Organización de Unión Africana (OUA). Sus fines fueron promover la unidad y la solidaridad de los Estados africanos y servir como vocería colectiva del continente (OWONOOKOMO, 2014, p. 51). Señala Okomo que también tenía como objetivo erradicar el colonialismo y promover la cooperación internacional (OWONOOKOMO, 2014, p. 51).

Sostiene la propia Unión Africana que los principales objetivos de la OUA según se establecen en su Carta fundacional son, entre otros: promover la unidad y la solidaridad entre los Estados africanos; coordinar e intensificar su cooperación y esfuerzo a fin de lograr una vida mejor para los pueblos africanos; salvaguardar la soberanía y la integridad territorial de los Estados miembro; liberar el continente del apartheid y de la colonización (AFRICAN UNION, 2014, p. 10).

Afirma Kabunda (2014, p. 18) que la OUA fue un triunfo de las tesis ultraconservadoras mayoritarias del Grupo de Monrovia/Brazaville ("moderados" proocidentales, partidarios de la integración paulatina a partir de las subregiones, enfoque considerado como realista) en contra de las propuestas maximalistas, minoritarias, del Grupo de Casablanca ("radicales" y progresistas defensores de la política continental inmediata), liderado por Osagyefo Kwame Nkruma.

Teniendo en cuenta que la creación de la OUA se dio en una época en la que la mayoría de los Estados africanos se encontraban en situación colonial, tan sólo 32 Estados independientes se adhirieron al proyecto en la época (KABUNDA, 2014).

En los años noventa los líderes africanos debatieron sobre la necesidad de actualizar las estructuras de la OUA en acorde con los desafíos de un mundo en cambio, sobre todo teniendo en cuenta que cuando de su creación varios Estados africanos todavía se encontraban 
bajo el yugo del colonialismo y, a nivel global se vivía en un mundo bipolar. En este sentido, desde 1999, diez años después de la caída del muro de Berlín, los jefes de estado y gobiernos africanos iniciaron el camino para la constitución de la Unión Africana (UA) con tres objetivos principales: acelerar el proceso de integración en África; apoyar el empoderamiento de los Estados africanos en la economía global; y debatir sobre los problemas multifacéticos de índole social, económico y político a nivel global (KABUNDA, 2014).

A fin de concretar el proyecto en cuestión se realizaron tres cumbres siendo: la Cumbre de Lomé en el año 2000, la de Lusaka en el 2001 y la de Durban en el año 2002 en la que se creó la actual Unión Africana. Kabunda (2014, p. 19) considera la UA una especie de "OUA bis" ya que se fundamenta en los principios de igualdad soberana, el respeto de independencia de cada país, y de su integridad territorial, principios que van en contra de una unidad continental real. Según él la UA privilegia la continuidad y permanencia de los Estados-nación superficiales y heredados de la colonización a la verdadera independencia económica y política del continente.

Finalizando esta línea introductoria creemos que es relevante mencionar que el sistema africano actual según su Carta fundacional se basa en los derechos de los pueblos y, por consiguiente, los de la comunidad, en contra de los principios individualistas. Consideramos éste un gran desafío ya que será necesario compaginarlo con los principios de globalización cultural que prioriza comportamientos individualistas incluso en los países del continente africano.

\section{Estructura de la Unión Africana}

La estructura orgánico-institucional de la Unión Africana al igual que la de la Unión Europea (es el mimetismo de ésta) es muy amplia y compleja. Por ello, en este apartado trataremos de exponer aquellos organismos que consideramos relevantes y con relación a la temática aquí presentada. Trataremos de exponer pues datos sobre la Carta Africana de los Derechos Humanos y de los Pueblos, la Comisión Africana y la Corte Africana de los Derechos Humanos y de los Pueblos. 


\subsection{Carta Africana de los Derechos Humanos y de los Pueblos}

La Carta Africana de los Derechos Humanos y de los Pueblos, también llamada Carta de Banjul (en adelante la Carta), nació fruto tanto de la presión internacional como de la necesidad a nivel continental de un instrumento de derechos humanos. La presión internacional vino de la Comisión Internacional de Juristas que ya en el año 1961 instó a los gobiernos africanos adoptar un tratado sobre derechos humanos, pero debido a los regímenes dictatoriales y otros obstáculos locales, no fue hasta el año 1981 cuando se aprueba y entra en vigor en el año 1986 (TARDIF, 2013; EUROPEAN PARLIAMENT, 2013).

Sostiene Baricako (2008, p. 6) que el texto final de la Carta toma en consideración tanto la diversidad ideológica y política de los países africanos como los principios que fundan las sociedades tradicionales del continente. De ahí el aspecto de los derechos de los pueblos frente al individualismo que mencionamos anteriormente.

Según señala Tardif (2013, p. 141), la Carta tiene cuatro características que merecen ser mencionadas:

1. Indivisibilidad de los derechos civiles y políticos (DCP) frente a los derechos económicos, sociales y culturales (DESC), y que la satisfacción del segundo grupo de derechos garantiza el goce de los del primero. Afirma Tardif que es un instrumento pionero al contemplar ambas categorías de derechos en un solo documento. Añadimos además que es uno de los pocos instrumentos en la materia que prioriza el ejercicio de los DESC frente a los DCP y, no al contrario como ocurre en los instrumentos normativos europeos.

2. La segunda característica está relacionada a lo que ya hicimos mención anteriormente, es decir, la referencia a los "derechos de los pueblos", "[...] vista la insistencia de los Estados socialistas y la concepción de que, en África, el individuo y sus derechos se encuentran cobijados en la protección que la familia y otras comunidades otorgan a todos [...]". 
3. La tercera característica tiene a ver con que la Carta establece que el individuo tiene deberes con otros individuos, con su familia y la comunidad internacional entera.

4. En cuarto y último lugar, la Carta no permite a los Estados desestimar sus obligaciones, salvo excepciones basadas en la protección de los derechos de otras personas, la seguridad colectiva, la moralidad y el interés común. Los principios aquí señalados se contraponen a los de seguridad, sanidad y orden públicos establecidos en los ordenamientos europeos.

Señala Tardif que la Carta ha sido criticada por ser modesta en sus objetivos y a la vez flexibles en sus medidas, menos desarrollada o efectiva, más controversial en su redacción, en comparación con los sistemas europeo e interamericano. En este sentido, la Carta da pie a múltiples interpretaciones (TARDIF, 2013, p. 142). Siendo firmes defensores de los Derechos Humanos material y contextualizados, creemos por un lado al igual que Tardif que es necesario contextualizar la elaboración, redacción y aprobación de la Carta en un contexto de guerra fría, colonialismo y apartheid (TARDIF, 2013, p. 142) y, por otro que la efectividad de un instrumento normativo no depende única y exclusivamente de sus buenas intenciones y/o sus aspectos jurídicos, sino igualmente del contraste con otros elementos de garantía de índoles socioeconómica, sociopolítica, sociocultural y democrática, aspectos todos ellos cuasi únicos en las sociedades africanas y, por consiguiente generan grandes desafíos a la Carta.

\subsection{Comisión Africana de los Derechos Humanos y de los Pueblos}

La Comisión Africana de los Derechos Humanos y de los Pueblos (en adelante Comisión) fue establecida de acuerdo con el art. 30 de la Carta de Banjul en al año 1987 y su principal objetivo es la vigilancia y la interpretación de la Carta de los Derechos Humanos y de los Pueblos mencionada en el apartado anterior.

La Comisión está compuesta por 11 miembros que son elegidos por la Asamblea de la UA entre los expertos propuestos por los Estados 
miembro (EUROPEAN PARLIAMENT, 2013). Al igual que en la Corte Europea de los Derechos Humanos, reiteramos que el nombramiento de un miembro de la Comisión por un Estado puede condicionar sus decisiones en el ejercicio de sus funciones.

La Comisión tiene un mandato cuasi jurisdiccional y, por lo tanto, sus recomendaciones finales no son legalmente vinculantes y no existen mecanismos que pueda obligar a los Estados a cumplir sus recomendaciones. Sin embargo, en situaciones de emergencia en que la vida de las víctimas se encuentre en peligro inminente, la Comisión puede invocar medidas provisionales bajo la Regla 111 de su Reglamento de Procedimientos requiriendo al Estado en cuestión que retrase cualquier acción pendiente de su decisión final en la materia (AFRICAN UNION, 2014, p. 74).

Igualmente, de acuerdo con sus nuevos procedimientos, la Comisión puede enviar informaciones sobre serias o masivas vulneraciones de los derechos humanos a la Ejecutiva de la UA o a la Corte Africana de los Derechos Humanos y de los Pueblos [...], aunque raramente hace uso de estas prerrogativas (EUROPEAN PARLIAMENT, 2013).

En sus funciones cuasi jurisdiccionales y de acuerdo con lo establecido en los artículos 47-49, la Comisión tiene prerrogativas para recibir comunicaciones provenientes de los Estados parte, ONG's y particulares.

Tardif (2013, p. 145) interpreta las funciones cuasi jurisdiccionales de la Comisión en acorde con el derecho consuetudinario africano, que tiende a privilegiar el mejoramiento de las relaciones entre las partes en base a la equidad y la buena consciencia, es decir perdonar y conciliar más que tecnicidades jurídicas.

De acuerdo con el art. 62 de la Carta, los Estados deben remitir a la Comisión cada dos años informes sobre medidas legislativas o de otra naturaleza a fin de garantizar derechos y libertades establecidos en la Carta. Hasta la presente fecha ocho Estados han presentado todos los Informes, quince están retrasados en la entrega de uno o dos Informes, 
veinte y cuatro están retrasados en la entrega de tres o más Informes y, siete nunca han remitido informes a la Comisión.

Otro desafío al que se enfrenta la Comisión es el débil acatamiento por parte de los Estados de sus recomendaciones que tal como expusimos antes no son vinculantes ni existen mecanismos que los obliga a cumplir.

\subsection{Corte Africana de los Derechos Humanos y de los Pueblos}

La Corte Africana de los Derechos Humanos y de los Pueblos (en adelante la Corte) fue establecida en 1998 y entró en vigor en el año 2004 y uno de sus principales objetivos es el de complementar y reforzar las funciones de la Comisión. La Corte puede realizar decisiones vinculantes, incluidas órdenes de reparación o compensación a diferencia de la Comisión que solo puede realizar recomendaciones, como vimos en el apartado anterior (AFRICAN UNION, 2014).

La Corte tiene jurisdicción en todos los casos y controversias (conflictos) a él sometidos relacionados con la interpretación y aplicación de la Carta Africana de los Derechos Humanos y de los Pueblos, del Protocolo que establece la Corte, o cualquier otro instrumento de los derechos humanos ratificados por el Estado en cuestión (AFRICAN UNION, 2014).

La Corte está compuesta por once jueces que son elegidos por la Asamblea de la UA, entre los juristas de renombre propuestos por los Estados parte del Protocolo de la Corte. En la elección de los once jueces la Asamblea tiene en cuenta criterios geográficos, de género y tradición legal (AFRICAN UNION, 2014).

De acuerdo con el art. 5 del Protocolo de la Corte, únicamente la Comisión, los Estados y las Organizaciones intergubernamentales pueden acceder a la Corte (TARDIF, 2013, p. 146). Añade la propia UA que Organizaciones No Gubernamentales con el estatus de observadores ante la Comisión e individuos de Estados miembro que hayan hecho la declaración aceptando la jurisdicción de la Corte, igualmente pueden acceder al Tribunal de acuerdo con lo establecido en el art. 34(6) del Protocolo (AFRICAN UNION, 2014). 
Hemos hecho referencia a dos cuestiones que son relevantes aclarar ya que constituyen piezas clave para el funcionamiento de la Corte de cara a la garantía de los derechos humanos y de los pueblos; se tratan de la firma por parte de los Estados del Protocolo de la Corte y, de los Estados que hayan reconocido la jurisdicción de la Corte. Hasta el año 2014 según la Unión tan solo $26^{2}$ de los 54 Estados miembro de la UA han ratificado el Protocolo de la Corte $y$, siete ${ }^{3}$ han reconocido la jurisdicción de la Corte permitiendo así a sus ciudadanos y las Organizaciones No Gubernamentales presentar quejas directamente a la Corte (AFRICAN UNION, 2014, p. 78).

Instituciones y organismos africanos vienen trabajando a fin de fundir la Corte Africana de Justicia (un organismo que actualmente no es operativo) y la Corte Africana de los Derechos Humanos y de los Pueblos, en Corte Africana de los Derechos Humanos y de los Pueblos. Pero empezará su funcionamiento cuando sea ratificada por 15 Estados miembro. Hasta el año 2013 tan sólo veinte y nueve Estados han firmado el Protocolo y cinco lo han ratificado (AFRICAN UNION, 2014).

Tras haber hecho ciertas aclaraciones sobre los antecedentes de la UA y la estructura de ésta última, en las siguientes líneas trataremos de exponer dos mecanismos que sirven para monitorear los regímenes políticos en el sistema africano, por un lado, el Sistema Africano de Revisión de Pares (APRM en sus siglas en inglés) y, por otro, las fuentes jurídicas de control en los accesos inconstitucionales al poder.

\section{Control de los Sistemas Democráticos en el Sistema Africano}

La situación de los sistemas democráticos en el continente africano es al menos preocupante. Según un estudio del Centro de Estudios Estratégicos sobre África (CESA, 2011) todavía existe en el continente africano un $10 \%$ de regímenes autocráticos y, la mayoría de los Estados,

\footnotetext{
${ }^{2}$ Argelia, Burkina Faso, Burundi, Islas Comores, Congo, Costa de Marfil, Gabón, Gambia, Ghana, Kenia, Lesoto, Libia, Malawi, Malí, Mauritania, Islas Mauricio, Mozambique, Níger, Nigeria, Ruanda, Senegal, Sudáfrica, Togo, Túnez, Uganda y Tanzania.

${ }^{3}$ Burkina Faso, Costa de Marfil, Ghana, Malawi, Mali, Ruanda y Tanzania.
} 
más del 30\%, tienen regímenes mixtos, es decir la combinación entre elementos autocráticos y democráticos. Los sistemas democráticos tan sólo constituyen el 8\% aproximadamente de los regímenes.

La mayoría de los regímenes en África son, según Kabunda, "democraturas", el acoplamiento entre democracias formales y dictaduras encubiertas (KABUNDA, 2014, p. 15).

Teniendo en cuenta este escenario y que constantemente se vive en el continente casos de instabilidad democrática a través de toma de poder inconstitucional, se han implementado, al menos, dos programas a fin de suplir esas deficiencias. Trataremos de explicarlos en las siguientes líneas.

\subsection{African Peer Review Mechanism (APRM) - Mecanismo Africano de Revisión de Pares}

APRM es la concreción de una de las principales preocupaciones de la Acta Constitutiva de la UA en materia de los sistemas democráticos. Fue instaurada en el año 2002 como parte del Nuevo Partenariado para el Desarrollo de África (NEPAD, en inglés) y, hoy en día es un programa independiente (EUROPEAN PARLIAMENT, 2013).

Como señala la propia UA, es la vía para que los Estados miembro revisen sus compromisos con la buena gobernanza. El APRM es un instrumento de auto monitoreo y la adhesión al mismo es voluntario (AFRICAN UNION, 2014, p. 114). Estos son, desde nuestro punto de vista, las principales debilidades del instrumento, el hecho que sean los propios Estados quiénes realicen el monitoreo de sus sistemas democráticos $\mathrm{y}$, la adhesión no es obligatoria sino voluntaria, haciendo que aquellos Estados que no pretenden revisar sus sistemas no se adhieran a él.

En este sentido, hasta septiembre de 2013, 35 Estados miembro de la UA se ha unido a la APRM, de los cuales 17 han completado la auto evaluación y han sido revisados por el Foro competente (AFRICAN UNION, 2014).

Señala la UA que la actuación y los progresos de los Estados en la materia son medidos en cuatro áreas estratégicas: democracia y gobernanza 
política; gobernanza económica y gestión; gobernanza corporativa; y el desarrollo socioeconómico. Las revisiones deben incluir tanto los ámbitos legislativo, ejecutivo y judicial de los gobiernos, así como el sector privado, la sociedad civil y los media (AFRICAN UNION, 2014).

Aunque no sea un instrumento vinculante, "[...] la APRM puede solicitar la revisión de petición de participación de los Jefes de Estados y Gobiernos en los organismos de la UA, caso existan muestras de inestabilidades económicas y políticas" (AFRICAN UNION, 2014, p. 114).

Además del APRM existen otros instrumentos jurídicos que tratan de contribuir a la mejoría del sistema democrático en el continente africano, algunos más vinculantes que otros. En las siguientes líneas trataremos de exponer algunos de ellos en base al estudio sobre la Carta Africana de la Democracia, Elecciones y Gobernanza realizado por Stef Vanderginste publicado en el año 2013 por el Journal of African Law.

\subsection{Declaración de Lomé}

Señala Vanderginste que antes de julio de 2000 la UA vivía en un régimen de estricta adhesión al principio de no interferencia en asuntos internos de los Estados miembro. A partir de julio de 2000 se establece una declaración de política general permitiendo la interferencia en materia relativa a la transferencia inconstitucional de poder. Pero, teniendo en cuenta que la toma de poder por los militares a través de coup d'État no es el único medio de acceso ilegal al poder, la Declaración de Lomé introdujo el concepto de cambio inconstitucional de poder. Sin embargo, hasta la fecha la labor de la Declaración tan sólo tiene en cuenta los golpes de Estado (VANDERGINSTE, 2013, p. 2).

La Declaración de Lomé fue creada en la $36^{\mathrm{a}}$ sesión ordinaria de la Asamblea de la UA que tuvo lugar en Lomé (Togo) entre los días 10 y 12 de julio del año 2000, es decir, antes de la transición entre la OUA por la UA.

La Declaración de Lomé estableció unos principios y valores comunes para la gobernanza democrática en el continente, como: la adopción y respeto por una Constitución democrática; la separación de poderes; el pluralismo democrático; la protección de los derechos 
humanos; y la organización de elecciones libres y regulares (VANDERGINSTE, 2013).

Como medidas concretas a fin de efectivar estos objetivos, en caso de cambios inconstitucionales de gobierno en un Estado miembro, la Declaración de Lomé puede requerir a la UA que condene dicho cambio y urgir a una rápida vuelta al orden constitucional. En el marco de este procedimiento se concede un periodo de seis meses a los perpetradores para restaurar el gobierno. Durante este periodo el gobierno en cuestión puede ser suspendido de su participación en los órganos políticos de la UA. Tras los seis meses, pueden ser impuestas una serie de sanciones determinadas contra el régimen que se niega en restaurar el orden constitucional, en la que incluyen: denegación de visados, restricciones comerciales y, restricciones en los contactos intergubernamentales (VANDERGINSTE, 2013, p. 3).

La institución encargada de implementar las medidas y políticas de la Declaración de Lomé es el Consejo de Paz y Seguridad de la UA (PSC, en inglés).

\subsection{Carta Africana de Democracia, Elecciones y Gobernanza}

La Carta Africana de Democracia, Elecciones y Gobernanza (en adelante Carta), fue adoptada en la octava sesión ordinaria de la Asamblea de los Jefes de Estado y de Gobierno en Addis Abeba el 30 de enero de 2007 y entró en vigor el 15 de febrero de 2012. Es curioso el tiempo que transcurre entre la adopción de un instrumento normativo y la entrada en vigor en el sistema africano, ello muestra la inercia de los Estados en el compromiso con los valores de la UA.

Sostiene Vanderginste (2013, p. 5-6) que, en comparación con la Declaración de Lomé, la Carta es más ambiciosa, ya que establece estándares sobre como el poder político debe ser ejercido $\mathrm{y}$, no simplemente como el poder político es transferido. Igualmente, en el marco del acceso ilegal al poder, añade enmiendas o revisiones a la Constitución $\mathrm{u}$ otros instrumentos legales que infrinjan los principios de cambio democrático de gobierno. 
Al igual que la Declaración de Lomé la Carta trabaja en consonancia con las reglas del Consejo de Paz y Seguridad de la UA. Así en el marco de las sanciones establecidas en el art. 25 de la Carta, sostiene que éstas pueden ser impuestas igualmente a aquellos Estados miembro que se demuestre apoyan cambios constitucionales de gobierno en otros Estados miembro (VANDERGINSTE, 2013, p. 7).

Además de los dos instrumentos aquí señalados, en el marco de garantía del orden constitucional en el sistema africano también se encuentran el Acta Constitutiva de la UA, el Protocolo Adicional de 9 de julio sobre el establecimiento del Consejo de Paz y Seguridad de la UA y, la Decisión 269 (XIV) de la Asamblea de la UA, de 2 de febrero de 2010.

Asegura Vanderginste (2013, p. 4) que “[...] el Acta Constitutiva de la UA [...] combina la "tradición de no interferencia como uno de los fundamentos para las relaciones entre Estados igualitarios y soberanos, con la "novedad" de no indiferencia de la UA".

Es decir, a pesar de respetar la soberanía de los Estados miembro, no es indiferente a las vulneraciones a los derechos humanos y los principios democráticos que ocurren en su seno. En este sentido, según se establece en el art. 30 de la Acta Constitutiva aquellos gobiernos que llegan al poder por vías inconstitucionales no deberán permitirse su participación en las actividades de la UA (VANDERGINSTE, 2013, p. 4).

Con relación al PSC, bajo el protocolo constitutivo de este organismo y en conjunción con la Presidencia de la Comisión Africana se deben instruir sanciones allí donde se haya producido cambios inconstitucionales de gobierno (VANDERGINSTE, 2013).

Y, finalmente, la Decisión 269 de la Asamblea de la UA es una medida para apoyar las actividades del PSC. La decisión en cuestión añade una importante sanción diplomática consistente en que "en caso de cambio inconstitucional de gobierno los Estados miembro no deben reconocer las autoridades de facto" y además deben apelar a todos organismos internacionales que no sean africanos incluyendo Naciones Unidas, de abstenerse a conceder acreditaciones a dichas autoridades (VANDERGINSTE, 2013, p. 7-8). 
En la mayoría de los instrumentos normativos aquí señalados hemos hecho referencia a la vuelta al orden constitucional como una de las medidas para la restauración del orden. Pues según Vanderginste la vuelta al orden constitucional puede llevarse a cabo por dos vías, siendo: la vuelta al estatus Constitucional quo ante, por un lado y, por otro, mediante la celebración de elecciones, posiblemente recurriendo a la compartición de poder. En la práctica varias comparticiones de poder son incompatibles con el orden constitucional del país en cuestión (sean regímenes presidencial o semi presidencial), por ello muchas veces es necesario vulnerar la Constitución a fin de instaurar el orden pacífico e institucional como ocurrió en Yamena (Chad) en el año 2007 y en Guinea Bissau en el año 20104.

A fin de complementar las informaciones aquí expuestas sobre el control de los sistemas democráticos por parte de los organismos de la UA, en las próximas líneas trataremos de exponer datos sobre la interpretación del derecho internacional y regional (UA) por parte de las Constituciones de los países lusos-africanos.

\subsubsection{Angola}

La República de Angola es uno de los cinco Estados luso-africanos y está situado al sur del continente, fronterizo con Namibia, República Democrático del Congo y Zambia. Su capital es Luanda.

La Constitución que aquí presentamos es la reforma realizada en el año 2010 de la Constitución de 1992 por la Asamblea Nacional de Angola. El art. 6. 1 de la Constitución angoleña reconoce a esta última (la Constitución) como la Ley suprema de la República de Angola. Dicho reconocimiento no significa impermeabilidad a las normas que provengan de otros ámbitos como puede ser el regional (Unión Africana) o internacional.

Así en su art. 12 se establece que Angola respeta y aplica los principios de la Carta de la ONU y de la Carta de la Unión Africana.

\footnotetext{
${ }^{4}$ A fin de profundizar sobre la temática y verificar las medidas tomadas cuando de las crisis constitucionales en el sistema africano, ver: VANDERGINSTE, Stef. The African Union, Constitutionalism and Power-Sharing. Journal of African Law, 2013.
} 
En este orden de idea en el art. 26 párrafo 1, 2 y 3 se establecen respetivamente que los derechos fundamentales constantes en la Constitución no excluyen otras reglas o leyes que se apliquen en el derecho internacional; que los derechos fundamentales establecidos en la Constitución deben ser interpretados en acorde con la Declaración Universal de los Derechos del Hombre y la Carta africana de los Derechos Humanos y de los Pueblos y finalmente; que en los litigios en los Tribunales angoleños la interpretación de los derechos fundamentales debe tener en cuenta los instrumentos internacional y regional antes mencionando. El art. 27 refuerza lo aquí expuesto estableciendo lo siguiente: "Los principios enunciados en este capítulo son aplicables a los derechos, libertades y garantías y a los derechos fundamentales de naturaleza análoga establecidos en la Constitución consagrados por ley o por Convención Internacional”.

El reconocimiento de la legislación regional e internacional antes mencionado se ratifica en el art. 13 que establece que el derecho internacional general o común (...) forma parte de la orden jurídica angoleña. El segundo párrafo del artículo en cuestión establece las condiciones para que las normativas regionales e internacionales formen parte del ordenamiento interno angoleño. En este sentido establece lo siguiente: "Los tratados y acuerdos internacionales regularmente aprobados o ratificados formarán parte de la orden jurídica angoleña tras su publicación oficial y entrada en vigor en el orden jurídico internacional y mientras vinculen a nivel internacional al Estado angoleño".

En un sentido material de la incorporación del derecho regional e internacional en el ordenamiento jurídico angoleño, en el art. 121. c se establece que es competencia del Presidente de la República firmar, ratificar, según los casos y tras su aprobación, los tratados, convenciones, acuerdos y otros instrumentos internacionales. La aprobación de los tratados, convenciones, acuerdos y otros instrumentos internacionales es de la competencia de la Asamblea Nacional en los ámbitos de su competencia legislativa absoluta (art. 161. j). Igualmente compete al poder legislativo en cuestión aprobar la desvinculación del Estado angoleño de los tratados, convenciones, acuerdos y otros instrumentos internacionales. 
El Consejo de Ministros puede pronunciarse sobre acuerdos internacionales cuya aprobación sea de la competencia del Presidente de la República (art. 134. 4. f).

Los tratados, convenciones, acuerdos y otros instrumentos internacionales antes de ser firmados y ratificados por el Presidente de la República pasarán por un proceso de fiscalización de constitucionalidad, es decir, a fin de verificar si se adecuan a los principios establecidos por la Constitución angoleña (art. 227. b).

En este proceso de fiscalización el Presidente de la República puede requerir al Tribunal Constitucional (TC) una fiscalización preventiva de constitucionalidad del acuerdo o tratado internacional que haya sido remitido para firma o ratificación (art. 228. 1.).

El tratado o acuerdo internacional no se incorporará al orden interno angoleño hasta que se haya pronunciado el TC. Caso el TC se pronuncie en contra de la adecuación constitucional de un tratado o acuerdo internacional, éste será vetado por el Presidente de la República (art. 229. 2.).

\subsubsection{Guinea Bissau}

Guinea Bissau está situado en la región del África Occidental y es fronterizo con Senegal y Guinea Conakry. Su capital es Bissau.

La Constitución con la que hemos trabajado en este texto es la versión que fue promulgada en el año 1984 y enmendada en los años 1991, 1993 y 1996. En la Constitución guineana no se reconoce explícitamente la supremacía de la Constitución tal como se expresa en la Constitución angoleña.

En cuanto a la conexión de la Constitución y el derecho internacional, se establece en el art. 29 que los derechos fundamentales consagrados en la Constitución no excluyen otros que consten en otras leyes de la República de la Guinea Bissau y de las reglas aplicables en el derecho internacional. El segundo párrafo del artículo en cuestión se establece la interpretación de los preceptos constitucionales y de los derechos constitucionales en harmonía con la Declaración Universal de los Derechos Humanos. 
Al igual que en la Constitución angoleña antes mencionada, en la guineana compete al Presidente de la República la ratificación de los tratados internacionales (art. 68. e). En las competencias del Presidente de la República en la materia no se hace referencia a la firma de los tratados y acuerdos internacionales, creemos que se debe interpretar la ratificación como implícita a la labor de firma por parte del Presidente.

La aprobación de los tratados también es de competencia de la Asamblea Nacional Popular de acuerdo con lo establecido en el art. 85. h) de la Constitución. Compete al gobierno en el marco del derecho internacional, negociar y concluir los acuerdos y convenciones internacionales.

\subsubsection{Cabo Verde}

Cabo Verde es un Estado insular situado frente a las costas senegalesas y compuesto por diez islas grandes y cinco menores. Las diez mayores y habitadas son: Santo Antão, São Vicente, Santa Lucia, São Nicolau, Sal, Boa Vista, Maio, Santiago, Fogo e Brava.

La Constitución que aquí presentamos es la Ley Constitucional n. 1/VII/2010 que modifica íntegramente la Constitución de 1992. Al igual que en la Constitución angoleña, la caboverdiana reconoce en su art. $3^{\circ}$. 3 la supremacía de la Constitución sobre las leyes y los demás actos del Estado, del poder local y de los entes públicos en general.

Dicha supremacía no es incompatible con el reconocimiento y aceptación del derecho regional e internacional en su ordenamiento interno. Así el art. $11^{\circ}$ - 1. establece que el Estado de Cabo Verde se rige por los principios de independencia nacional, del respeto por el derecho internacional y por los derechos humanos.

Igualmente, la interpretación de los derechos y libertades establecidos en la Constitución se hacen conforme los instrumentos regionales e internacionales. En este sentido, el art. 17. 1 formula "que las leyes o convenciones internacionales podrán consagrar derechos, libertades y garantías que no estén previstos en la Constitución”. El punto tercero del artículo en cuestión dispone que las normas constitucionales 
y legales relativas a los derechos fundamentales deben ser interpretadas e integradas en harmonía con la Declaración Universal de los Derechos Humanos. Los compromisos con el ámbito internacionales establecidos en el art. 17 es ratificado en el art. 25 cuando dispone que los principios del título II en torno a los principios generales sobre derechos y deberes fundamentales, se aplican a los derechos, libertades, garantías individuales y derechos fundamentales, tanto los establecidos en la Constitución como en las Convenciones internacionales.

Con lo expuesto en el párrafo anterior podemos deducir lo que se fija en el art. 12.1 según el cual el derecho internacional general o común es parte integrante del ordenamiento jurídico caboverdiano mientras esté en vigor en orden internacional. Sin embargo, dicha aceptación no es automática, es necesario un proceso que trataremos de explicar en el siguiente párrafo.

El párrafo segundo del art. 12 dispone que los tratados y acuerdos internacionales aprobados válidamente o ratificados entrarán en vigor en el ordenamiento jurídico caboverdiano tras su publicación oficial $\mathrm{y}$ entrada en vigor en el orden jurídico internacional y mientras sea vinculante al Estado caboverdiano.

Es menester resaltar el contenido del apartado cuarto del art. 12 que dispone sobre la prevalencia de los principios del derecho internacional general o común aprobados válidamente o ratificados por el Estado caboverdiano, sobre todos los actos legislativos y normativos internos de valor infraconstitucional.

El art. 13 de la Constitución caboverdiana establece que la adhesión del Estado a cualquier tratado o acuerdo internacional debe ser aprobada previamente por el órgano constitucional competente. En este sentido, es competencia del Presidente de la República en el ámbito de relaciones internacionales, la ratificación, tras la aprobación, de los Tratados y Acuerdos internacionales (art. 135. a). La aprobación de Tratados y Acuerdos internacionales es de la competencia de la Asamblea Nacional al igual que en las Constituciones angoleña y guineana (art. 174. h). Lo establecido en el art. 174.h, es ratificado y reforzado en el art. 178 que es competencia de la Asamblea Nacional la aprobación para ratificación 
de los tratados y acuerdos internacionales; la aprobación para ratificación o adhesión de otros tratados o acuerdos internacionales que sean de su competencia y que el gobierno requiera su apreciación; y aprobar la desvinculación de los tratados y acuerdos internacionales.

El gobierno en la Constitución caboverdiana también juega un papel importante en la internalización de los tratados y acuerdos internacionales. Así, el art. 202. J, y, k establecen que cabe al gobierno negociar y ajustar las Convenciones internacionales, así como aprobar, por decreto, los tratados y acuerdos internacionales cuya aprobación no sea de la competencia de la Asamblea Nacional. La aprobación por decreto aquí dispuesta es regulada en la competencia legislativa del gobierno establecida en el art. 203. 2. d). La acción de aprobación en sí es efectuada por el Consejo de Ministros (art. 205. e).

Para que surtan los efectos legales y forme parte del ordenamiento interno, los Tratados y Acuerdos internacionales deben ser publicados en el Boletín Oficial de la República de Cabo Verde, según se dispone en el art. 264.1. c).

Antes de la firma, ratificación, aprobación e internalización de cualquier norma internacional en el ordenamiento jurídico caboverdiano, este debe pasar por la fiscalización preventiva de constitucionalidad que el Presidente de la República requiere al Tribunal Constitucional (art. 273.1.a). En este sentido el art. 274. 1. establece que si el Tribunal Constitucional se pronunciar sobre la inconstitucionalidad de la norma constante en el tratado o acuerdo internacional, éste no debe ser ratificado, siendo pues devuelto al órgano que lo haya aprobado, que puede ser la Asamblea Nacional o el gobierno. A pesar de este requerimiento previo, el art. 272.2. dispone que la inconstitucionalidad orgánica o formal de los tratados o acuerdos internacionales que sean de competencias reservadas de la Asamblea Nacional o de la competencia legislativa del gobierno no impide la aplicación de sus normas en el ordenamiento jurídico interno caboverdiano desde que sean confirmados por el gobierno y aprobados en la Asamblea Nacional por dos tercios de los diputados presentes en la primera sesión plenaria tras la publicación de la decisión del Tribunal Constitucional. 


\subsubsection{Mozambique}

La República de Mozambique es al igual que Angola un Estado del sur del continente africano, pero a diferencia de Angola es bañado por el Océano Indico. Es fronterizo con varios países entre los que constan Tanzania, Zimbabue, Malawi, Zambia, Suazilandia y Sudáfrica.

La versión de la Constitución con la que hemos trabajado en este artículo es del año 2004, reforma de la Constitución del año 1990. En una línea similar a las Constituciones de Angola y de Cabo Verde, la Constitución de Mozambique es explícita en cuanto a la supremacía de su Constitución según lo establecido en el art. 2.2.

Al igual que en los casos anteriores dicha supremacía no impide la aplicación del derecho regional e internacional. Así, en el art. 17.2 establece que la República de Mozambique acepta, observa y aplica los principios de la Carta de la ONU y la Carta de la Unión Africana. Lo aquí expuesto es reforzado por el articulo 18 sobre derecho internacional. Éste último dispone que los tratados y acuerdos internacionales aprobados y ratificados válidamente, entran en vigor en el ordenamiento jurídico mozambiqueño tras su publicación oficial y mientras estén vinculados internacionalmente al Estado mozambiqueño. El segundo párrafo del art. 18 dispone que las normas del derecho internacional tienen, en el ordenamiento jurídico interno, el mismo valor que asumen los actos normativos infraconstituionales que emanen de la Asamblea de la República o del gobierno, según su respetiva forma de recepción.

El derecho internacional es tan parte del derecho interno mozambiqueño que los preceptos constitucionales relativos a los derechos fundamentales son interpretados e integrados en harmonía con la Declaración Universal de los Derechos Humanos y Carta Africana de los Derechos Humanos y de los Pueblos (art. 43).

Tal como expusimos antes, la incorporación del derecho internacional en el derecho interno mozambiqueño requiere de su aprobación y publicación oficial. Pues, por un lado, compete al Presidente de la República celebrar los tratados internacionales (art. 162. b), y a la Asamblea de la República ratificar y denunciar los tratados 
internacionales. A diferencia de Angola, Cabo Verde y Guinea Bissau donde las ratificaciones son tarea del Presidente de la República, en Mozambique esta tarea le incumbe a la Asamblea de la República.

En el marco de los tratados y acuerdos internacionales compete al gobierno preparar la celebración de tratados internacionales y celebrar, ratificar, adherir y denunciar los acuerdos internacionales en materias de su competencia gubernativa.

A pesar de que no haga referencia explícita sobre los tratados y acuerdos internacionales, creemos que el contenido del primer apartado del art. 246 hace referencia a que antes que los acuerdos internacionales sean celebrados por el Presidente de la República éste puede requerir una verificación preventiva de constitucionalidad al Tribunal Constitucional. Caso el Tribunal Constitucional declare su inconstitucionalidad veta su celebración y lo devuelve a la Asamblea de la República.

\subsubsection{Santo Tomé y Príncipe}

Santo Tomé y Príncipe es al igual que Cabo Verde un Estado insular compuesto por dos islas y varios islotes. Se sitúa en el golfo de Guinea y es bañado por el océano atlántico.

La versión de la Constitución que aquí presentamos es fruto de la reforma realizada en el año 2003 por la Ley 1/2003 que modifica la Constitución del año 1990. Al igual que en la Constitución de la Guinea Bissau la Constitución santotomense no declara de forma explícita la supremacía de la Constitución sobre las leyes infraconstitucionales u otras normas.

En cuanto al ámbito internacional, el art. 12. 2 establece que la República Democrática de Santo Tomé y Príncipe proclama su adhesión a la Declaración Universal de los Derechos Humanos y a los principios y objetivos de la Unión Africana y de la ONU. A diferencia de otros países que se adhieren a los instrumentos normativos de las Organizaciones regionales e internacionales aquí mencionadas, en el caso de Santo Tomé y Príncipe la adhesión se hace a la totalidad de sus principios y objetivos. 
Sobre la recepción del derecho internacional en el ordenamiento interno, se establece en el art. 13 que las normas y los principios del derecho internacional general o común son parte integrante del derecho santotomense. Además, se dispone que las normas que constan en las Convenciones, tratados y acuerdos internacionales debidamente aprobados y ratificados por los respetivos órganos competentes, entrarán en vigor en el ordenamiento santotomense tras su publicación oficial y mientras sigan vinculados internacionalmente al Estado santotomense.

Es menester resaltar al igual que en el caso caboverdiano el contenido del tercer apartado del art. 13. Éste último establece que las normas que constan en las Convenciones, Tratados y Acuerdos internacionales y debidamente aprobados y ratificados por los respetivos órganos competentes tienen prevalencia, tras su entrada en vigor en el orden internacional e interno, sobre todos los actos legislativos y normativos internos de valor infraconstitucional.

Tal es la simbiosis entre el derecho internacional y el derecho interno en el caso santotomense que, por un lado, los derechos consagrados en la Constitución santotomense no excluyen cualesquiera otros derechos que estén previstos en leyes o en reglamentos del derecho internacional y, por otro, la interpretación de los derechos fundamentales establecidos en la Constitucional debe hacerse en harmonía con la Declaración Universal de los Derechos Humanos.

Al igual que en otros países luso-africanos la incorporación del derecho internacional en el derecho interno requiere unos procedimientos establecidos por las Constituciones y las leyes correspondientes. Así, en Santo Tomé y Príncipe, compete al Presidente de la República la ratificación de los tratados internacionales tras su debida aprobación. La aprobación de los tratados internacionales es competencia de la Asamblea Nacional según lo dispuesto en el art. 97. j).

Es competencia del gobierno en materia internacional la negociación y la conclusión de los acuerdos y convenciones internacionales (art. 111. e).

Antes de la ratificación por el Presidente de la República éste puede requerir al Tribunal Constitucional la fiscalización preventiva de 
constitucionalidad o legalidad de los tratados internacionales (art. 80 . i). Lo aquí expuesto se refuerza en el contenido del art. 145. 1. de la Constitución. Si el Tribunal Constitucional declare la inconstitucionalidad de la norma o acuerdo internacional, el Presidente de la República lo vetará y lo devolverá al organismo que lo haya aprobado, en este caso a la Asamblea Nacional. A pesar de esta regla el art. 144.2 dispone que la inconstitucionalidad orgánica o formal de los tratados internacional debidamente ratificados no impide la aplicación de sus normas en el ordenamiento jurídico interno santotomense, desde que tales normas sean aplicadas en la orden jurídica de otra parte y salvo que tal inconstitucionalidad resulte violatoria de una disposición fundamental.

\section{Conclusión}

Hay que señalar que el Sistema Africano de Protección a los Derechos Humanos aún es reciente si lo comparamos a los Sistemas europeo y mismo el interamericano. Aunque el sistema sea reciente el Tribunal ya ha juzgado algunos casos sobre violaciones a los derechos humanos, contenidos en informes ${ }^{5}$. Asamblea respecto a sus trabajos. Los primeros informes son del año de 2004 y están publicados en el sitio de internet hasta el año de 2013.

Las actividades jurisdiccionales del Tribunal Africano de Derechos Humanos son recientes. Como ejemplo, de acuerdo con los informes del 2013, se puede examinar que han sido realizadas cinco sesiones de juzgados durante el 2013, con el análisis de siete procesos judiciales y dos procesos consultivos (CORTE AFRICANA DOS DIREITOS HUMANOS E DOS POVOS, 2013a). Actualmente hay un total de veinte y nueve procesos contenciosos y seis de naturaleza consultiva en trámite en el Tribunal, de los cuales se pronunció en un total de cinco procesos de naturaleza jurisdiccional y uno de naturaleza consultiva.

${ }^{5}$ Los casos allí se presentan nos informes de la Comisión. Información disponible en: http://www.african-court.org/pt/index.php/2012-03-04-06-07-42/activity-reports. Acceso en: 20 feb 2020. 
Durante el año de 2013 el Tribunal realizó un total de ocho audiencias públicas en algunos Estados de la Unión Africana. Respecto al incumplimiento de las decisiones del Tribunal, hay que aclarar que de acuerdo con el artículo 31 del Protocolo el Tribunal deberá comunicar los casos de incumplimiento de las decisiones, por parte de los Estados a la Conferencia.

En este sentido, importante mencionar el caso del Proceso 02/2013, de la Comisión contra Líbia, respecto a la detención del Señor Saif alIslam Ghadafi. En sede de medidas provisionales el Tribunal decidió que el Estado tendría que: a) no adoptar investigaciones o medidas judiciales para causar daños al investigado, incluso físicos, mentales o respecto a su salud b) permitir al detenido recibir sus familiares, así como un abogado, c) presentar las respuesta respecto a la adopción de las medidas en 15 días (CORTE AFRICANA DOS DIREITOS HUMANOS E DOS POVOS, 2013b).

Después de las notificaciones, Libia incumplió la decisión y en la $30^{a}$ Sección Ordinaria del Tribunal, este se manifestó respecto a la preocupación sobre el incumplimiento de la decisión y nada más.

Hay que señalar que ni todos los países de lengua portuguesa aceptan la jurisdicción del Tribunal como obligatoria. De acuerdo con el informe del Tribunal de 2013 (CORTE AFRICANA DOS DIREITOS HUMANOS E DOS POVOS, 2013b), solamente Mozambique ratificó el Protocolo sobre la jurisdicción del Tribunal, lo que hace difícil la aplicación del llamado control de constitucionalidad de las decisiones de la Corte o, además, de la propia aplicación de los Tratados de Derechos Humanos en el Sistema Africano.

Además, la propia actuación del Tribunal aún es tímida, respecto a la actuación en procesos de naturaleza jurisdiccional o consultiva. La realidad es sencilla: necesario que otros países de la Unión Africana vengan a ratificar el Protocolo. Ojalá la propria Corte Interamericana de Protección a los Derechos Humanos, del Sistema Interamericano de Protección a los Derechos Humanos, podría realizar acuerdos de cooperación con la Unión Africana, incluso dentro de los países de lengua portuguesa. 
Respecto a esto, la propia Comunidad de los Países de Lengua Portuguesa (CPLP), con liderazgo de Brasil y Mozambique, podrían realizar negociaciones en este sentido ${ }^{6}$.

Por fin, hay que aclarar que el tema del control de convencionalidad en la Unión Africana es novedoso y necesario una mayor consciencia de la propia sociedad, abogados, juristas y jueces respecto a la necesitad e a la importancia de aplicar los tratados de derechos humanos, ratificados por los Estados. Constitucionalmente puede verificarse que los ordenamientos jurídicos de los Estados del continente africano, de lengua portuguesa, permiten la aplicación del derecho internacional de los derechos humanos dentro de sus ordenamientos jurídicos, siendo necesario la existencia de una conciencia de la sociedad de os países de África de lengua portuguesa sobre la importancia del tema.

\section{Referencias}

AFRICAN UNION. African Union Handbook 2014. Ethiopia: African Union Commission and New Zeland Crown, 2014.

BARICAKO, Germain. The African Charter and African Commission on Human and People's Rights. In: EVANS, Malcom; MURRAY, Rachel. The African Charter on Human and People' Rights: the system in practice. 1986-2006. 2. ed. New York: Cambridge and University Press, 2008. p. 1-19.

CENTRE D’ÉTUDES STRATEGIQUES D’AFRIQUE (CESA).

L'Afrique et le printemps árabe: une nouvelle ère d'espoir democratique. Washington: CESA, 2013.

CORTE AFRICANA DOS DIREITOS HUMANOS E DOS POVOS. Informe 2013. 2013a. Disponível em: http://www.africancourt.org/pt/ images/documents/Reports/AfCHPR_Report_2013_Portuguese.pdf. Acesso em: 12 mar. 2015.

\footnotetext{
${ }^{6}$ A respecto de la Comunidad de los Países de Lengua Portuguesa (CPLP), ver en: https:// www.cplp.org/. Acceso em: 16 mar. 2020.
} 
CORTE AFRICANA DOS DIREITOS HUMANOS E DOS POVOS. Proceso 02/2013. 2013b. Disponível em: https://pt.african-court.org/ index.php/55-finalised-cases-details/856-app-no-002-2013-the-africancommission-on-human-and-peoples-rights-v-libya-detals. Acesso em: 22 abr. 2020.

\section{EUROPEAN PARLIAMENT. Human rights protection mechanism} in Africa: strong potential, weak capacity. [S.l.]: European Parliament, 2013.

KABUNDA, Mbuyi. Introducción. Algunos ámbitos de trabajo de la Unión Africana a debate. In: OWONO-OKOMO, Mansueto Nsí (coord.) Unión Africana: retos para la integración en materia de justicia, paz y desarrollo. Murcia: Editora Um., 2014. p. 13-45.

OWONO-OKOMO, Mansueto Nsí (coord.) Unión Africana: retos para la integración en materia de justicia, paz y desarrollo. Universidad de Murcia: Edit. Um., 2014.

TARDIF, Eric. Acercamiento al sistema africano de protección de los derechos humanos: avances y reto. Anuario de Derechos Humanos, México, n. 9. 139-148, 2013.

VANDERGINSTE, Stef. The African Union, Constitutionalism and Power-Sharing. Journal of African Law, [S.l.], 2013.

Eduardo Biacchi Gomes é pós-doutor pela Universidade Federal de Rio de Janeiro. Doutor em Direito. Professor do Programa de Pós-Graduação em Direito Constitucional da UniBrasil.

E-mail: eduardobiacchigomes@gmail.com

Endereço profissional: Rua Konrad Adenauer, n. 442, Taruma, Curitiba, PR. CEP: 82821-020.

ORCID: https://orcid.org/0000-0003-4044-8160 
Edileny Tomé da Mata é pós-doutor pela UniBrasil. Doutor europeu pela Universidade Pablo de Olavide na Espanha. Professor da Universidade Pablo de Olavide, Sevilla, Espanha.

E-mail: edtomata@gmail.com

Endereço profissional: Carretera de Utrera km 1, Sevilha, Andaluzia, 41013, Espanha.

ORCID: https://orcid.org/0000-0002-4217-3036 